\title{
Implications of vitamin D Deficiency on Egyptian Adults' Health
}

Sahar S. Ganeb, Refaat M. Eltanawy' Yasmin M. Marei, Hadir M.Abdelazez, Marwa Y. Mahgoub

Department of Rheumatology, Rehabilitation and Physical Medicine , Faculty of Medicine, Benha University, Egypt.

Correspondence to: Sahar S. Ganeb, Department of Rheumatology, Rehabilitation and Physical Medicine, Faculty of Medicine, Benha University, Egypt.

Email:

sahar_ganeb@yahoo.com

Received: 17 August 2020

Accepted: 2July 2021

\begin{abstract}
Aim: Highlighting some health consequences of hypovitaminosis D on adult Egyptian population. Methods: Fifty-five apparently healthy volunteers aged from 20 to 40 years were involved in the study. By history and physical examination 40 of them had mild clinical manifestation of negligible medical importance that affect the quality of their life without interfering with their daily activity. All volunteers were subjected to vitamin D and calcium dietary intake history, sun exposure assessment, body mass index (BMI), serum vitamin D and calcium profile, bone mineral density measured by Dual-energy X-ray absorptiometry (DXA), psychometric evaluation by the Beck Depression Inventory (BDI) score and physical activity evaluation by the International Physical Activity Questionnaire (IPAQ). Results: About $73 \%$ of our subjects had hypovitaminosis D (61.8\% insufficient and $10.9 \%$ deficient). The prevalence was more in the female gender (OR 4.5; $\mathrm{p} \leq 0.05)$, older subjects (31-40) age group (OR 4.4; $\mathrm{p} \leq 0.05)$, with poor sun exposure (OR 7.8; $\mathrm{p} \leq 0.05$ ), and low vitamin $\mathrm{D}$ and
\end{abstract} calcium dietary intake (OR 4.6; $\mathrm{p} \leq 0.05$ ). Vitamin $\mathrm{D}$ deficient group showed the higher prevalence of obesity (45.5\%). Osteopenia was detected in seven subjects (14.3\%) who had low vitamin D levels. Vitamin D status had a negative correlation $(r=-0.653 ; p=<0.001)$ with the Beck score, and a positive correlation $(r=0.430 ; \mathrm{p}=0.001)$ with the IPAQ score. Conclusion: Hypovitaminosis D is a frequent condition in the healthy Egyptians that implicates their physical, functional, mental, and emotional health.

Keywords: Vitamin D Deficiency, hypovitaminosis D, mental health, functional status, bone mineral density. 


\section{Introduction}

Vitamin D is a fat-soluble vitamin that is distributed in the serum, muscle, liver, and fat tissue [1]. It is essential for bone mineralization in children and adolescents as it promotes the calcium absorption in the intestine. Sunlight exposure is the primary contributor to vitamin D nutritional status of most free-living individuals worldwide [2].

Low vitamin D status remains a global health problem that burdens more than one billion children and adults worldwide. Among Egyptians, vitamin D deficiency is a frequent adult's problem, for who especially exposed to inadequate sun exposure, inactive lifestyle, unhealthy eating habits and insufficient dietary calcium intake [3]. Numerous conditions may also contribute to low serum levels of vitamin D including extreme age, seasonal variations, dark skin pigmentation, clothing style (veiled females), obesity and malabsorption morbidities [4].

Vitamin D controls the mineral homeostasis and bone metabolism by increasing the intestinal calcium absorption and mediating the active reabsorption of calcium in the kidney. Also, it affects the bone formation and resorption by promoting the differentiation of osteoblasts and activation of the osteoclasts via RANKL production [5]. Vitamin D inhibits synthesis and secretion of parathyroid hormones $(\mathrm{PTH})$ in the parathyroid gland that reduces bone resorption [6].

Additionally, vitamin D regulates both innate and adaptive immunity. The innate immune response is characterized by the activation of monocytes and macrophages, which can recognize pathogen-associated molecular patterns and thus provide the first line of defense against outside agents, increasing the antimicrobial activity of macrophages and enhancing the chemotactic and phagocytic capacity of these cells. Adaptive immunity is also influenced by vitamin $\mathrm{D}$ by acting on cells of the monocyte-macrophage linkage preventing differentiation into dendritic cells and decreasing antigen presentation and $\mathrm{T}$ and $\mathrm{B}$ cell activity [7].

Also, vitamin D has trophic functions that are related to neuronal differentiation, maturation and growth [8]. It mediates the synthesis of a variety of neurotransmitters, including acetylcholine, catecholamines, serotonin and dopamine [9]. It has a 
neurotrophic role through the synthesis of nerve growth factor (NGF) [10], intracellular calcium homeostasis [11], prevention of oxidative damage to nervous tissue [12], and expression of genes and proteins involved in neuronal structure, physiological function, and metabolism [13]. In the same area, vitamin D deficiency has been correlated with worsening of Alzheimer's disease and memory, both of which can lead to increased falls and fractures [10]. Besides, vitamin D deficiency worsens depression and mental healthrelated quality of life (QoL) among people [14].

Additionally, many medical conditions accompany the hypovitaminosis D status like osteopenia, osteoporosis, risk of falls, type 1 diabetes mellitus, insulin resistance, obesity, common solid cancers, cardiovascular disease, hypertension, multiple sclerosis, depression, autoimmune, and infectious diseases [15].

So, we aimed to focus on the effects of decreased levels of vitamin $\mathrm{D}$ on the functional and mental status of the healthy Egyptian population.

\section{Subject and Methods:}

\section{Subjects:}

This is a cross-sectional study, carried out on 55 apparently healthy volunteers aged from 20 to 40 years randomly recruited from the medical staff and persons who accompanied the patients attending the inpatients' and outpatients' clinic of Rheumatology, Rehabilitation and Physical Medicine Department, Benha University Hospitals from February to August 2019. Subjects with acute or chronic illnesses, intestinal malabsorption, family history of hypocalcemia, vitamin D deficiency disorders, history of medications influencing bone metabolism (as calcium or vitamin D supplements, anticonvulsants, or corticosteroids) or pregnant females were excluded.

Written informed consents were obtained from all the subjects. This study was approved by the ethical committee of Faculty of Medicine, Benha University.No:16.10.18.

\section{Methods}

\section{Clinical assessment:}

A full history taking, general and physical examinations were carried out for all participants in the study. They were asked 
about their full medical history including the menstrual history of the females and the family history for conditions suggesting vitamin $\mathrm{D}$ deficiency like osteomalacia or fractures. The nutritional history of the dietary calcium and vitamin D intakes was stressed on and was categorized according to the Institute of Medicine recommendations [16] to: poor for no intake, fair for $\leq 600$ IU/day or good for $>600 \mathrm{IU} /$ day. Vitamin D and calcium supplement intakes were designated as 'yes' for taking a supplement or 'no' for not taking a supplement. Sun exposure was defined as poor for no exposure, fair for once per week or good for twice or more per week exposure of arms and legs to 0.5 minimal erythemal dose (MED) between the hours of 10 am and 3 pm. [17].

Clinical examination was directed to examine skin for color \& texture. Body mass index (BMI) was calculated and categorized as underweight $<18.5 \mathrm{~kg} / \mathrm{m}^{2}$, normal weight 18.5 to $24.9 \mathrm{~kg} / \mathrm{m}^{2}$, overweight 25 to 29.9 $\mathrm{kg} / \mathrm{m}^{2}$, and obese $\geq 30 \mathrm{~kg} / \mathrm{m}^{2}$.

\section{Laboratory assessment:}

Venous blood samples were obtained from all volunteers. The laboratory parameters included complete blood picture, kidney function tests, liver function tests, total serum calcium, serum phosphorus (P), alkaline phosphatase (ALP), parathormone hormone (PTH) and (25-OH) Vitamin D.

For vitamin D (25-OH) measurement, blood samples were collected from each participant by clean venipuncture using a disposable plastic syringe and put into a plain sterile tube (without anticoagulant) for serum separation. The tube was left at room temperature for 30 minutes till coagulation, and then centrifuged at $3000 \mathrm{rpm}$ for 30 minutes. The resultant serum was stored at $-20^{\circ} \mathrm{C}$ until analysis. All methods were performed according to the manufacturer's instructions. Serum vitamin D was measured using the "Enzyme Immunoassay for the Quantitative Determination of total 25-OH Vitamin D in Human Serum and Plasma" Cat. No. 10501, which is provided by Perfect Ease Biotec, (Beijing) Co., Ltd". Serum 25(OH) D level was classified into vitamin $\mathrm{D}$ deficiency $(\leq 20 \mathrm{ng} / \mathrm{mL})$, insufficiency (21-29 $\mathrm{ng} / \mathrm{mL}), \quad$ and sufficiency $(\geq 30 \mathrm{ng} / \mathrm{mL})[\mathbf{1 8}]$.

\section{Special assessments}

\section{Beck Depression Inventory (BDI) Questionnaire}

The Arabic translation of Beck's Depression Inventory-II (BDI-II) (a 21-item self-report instrument) [18] was used in this study for 
assessment of depression. The standard cutoff scores to determine the depression's severity were [0-10: normal, 11-16: mild mood disturbance, 17-20: border clinical depression, 21-30: moderate depression, 3140: severe depression, over 40: extreme depression] [19].

\section{International Physical Activity Questionnaire (IPAQ)}

Assessment of physical activity in the last 7 days in adults and adolescents was done using the International Physical Activity Questionnaire (IPAQ) short form it is a 9 items self-report [20] which measured the physical activity as low, moderate, and vigorous intensity level and it included both the frequency and the time spent doing that activity.

\section{Evaluation of bone mineral density}

Using dual X-ray absorptiometry (DXA) scanner at left distal forearm, lumbar spine, and neck of left femur. Bone Mineral Density (BMD), Z-score and T-score were recorded [21]. The T-score defines its unit as the standard deviation (SD) from the normal bone density. It was classified into: normal (a T-score of -1.0 SD or higher), osteopenia (between -1.0 SD and $-2.4 \quad$ SD), osteoporosis (a T-score of $-2.5 \mathrm{SD}$ or less) and severe osteoporosis (a T-score of -2.5 SD or less with a fragility fracture) [22].

\section{Statistical Analysis}

The collected data were tabulated and analyzed using an SPSS computer program (version 16; SPSS Inc., Chicago, IL, USA). Parametric variables were expressed as mean \pm standard deviations, while nonparametric were presented as median and range. Odds ratio (OR) and the corresponding $95 \%$ CI were calculated. Correlation computes the value of the Pearson's correlation coefficient $(r)$. In the statistical comparison: Inter-group comparison of categorical data was performed by using Chi square test $\left(\mathrm{X}^{2}\right)$, or Fisher's exact test (FET). Quantitative data were tested for normality using ShapiroWilks test. Difference among 3 independent groups was analyzed using ANOVA for parametric variables followed by Bonferroni tests or Kruskal Wallis test (KW) for nonparametric ones followed by Dune test. A $p$ value $\leq 0.05$ was considered statistically significant while $>0.05$ statistically insignificant and $\leq 0.001$ was considered highly significant in all analyses. 


\section{Results}

This study was conducted on 55 apparently healthy volunteers. Thirty-six (65.5\%) were females and 19 (34.5\%) were males, with a mean \pm SD age of $31.5 \pm 5$ years. Thirty-one subjects (56.4\%) were between 20 and 30 years, and 24 subjects (43.6\%) were between 31 and 40 years.

Subjects in the study were classified into 2 groups, Table 1):
Group I: Forty subjects (72.7\%) who have low levels of vitamin D [61.8\% had insufficient levels with a median level of $26.6(20.5-27.3 \mathrm{ng} / \mathrm{ml})$ and $10.9 \% \mathrm{had}$ deficient levels with a median level of $19.5(6.6-19.9 \mathrm{ng} / \mathrm{ml})]$. They were 6 females (40\%) and 9 males (60\%).

Group II: Fifteen subjects (27.2\%) who have normal levels of vitamin $\mathrm{D}$ [median level of $32(30.1-36.5 \mathrm{ng} / \mathrm{ml}]$. They were 30 females (75\%) and 10 males (25\%).

Table 1: Description of Vitamin D level in each category among the studied group

\begin{tabular}{|c|c|c|c|c|c|c|}
\hline \multicolumn{2}{|c|}{ Variable } & \multicolumn{2}{|c|}{ No. $(N=55)$} & $\%(100 \%)$ & Median & Rang \\
\hline \multirow{3}{*}{$\begin{array}{c}\text { Vit D status } \\
(\mathbf{n g} / \mathbf{m l})\end{array}$} & \multirow{3}{*}{$\begin{array}{c}\text { Group I } \\
\text { Group II }\end{array}$} & Sufficiency & 15 & 27.3 & 32.0 & $30.1-36.5$ \\
\hline & & Insufficiency & 34 & 61.8 & 26.6 & $20.5-27.3$ \\
\hline & & Deficiency & 6 & 10.9 & 19.55 & $6.6-19.9$ \\
\hline
\end{tabular}

By history, clinical examination, and completion of the designated questionnaires, it was found that near $70 \%$ of the subjects had mild clinical manifestations that affected the quality of their life without interfering with their activity of daily living, (figure 1).

Forty-three (78.2\%) subjects had a high BMI (32.72\% overweight and $45.45 \%$ obese) and a notable low vitamin D levels. There were statistically significant differences $(p=0.001)$ among subjects with normal vitamin $\mathrm{D}$ levels and those with low levels as regard to BMI being higher in the latter group (Table 2).

In the low vitamin D level group, comparison of the frequency insufficient and deficient levels regarding the BMI was statistically insignificant $(p=0.299)$, (Table 3). Concerning the calcium profile, there was statistical differences between normal and low vitamin D 
groups. The total Ca level $(\mathrm{p} \leq 0.001)$ and the ionized $\mathrm{Ca}$ level $(\mathrm{p} \leq 0.05)$ were significantly lower in low vitamin D group, while the ALP level $(\mathrm{p} \leq 0.001)$ was significantly higher in the same group. There was no statistically significant difference $(\mathrm{p}>0.05)$ between the studied groups as regards to the PTH level. Notably, we found that $87.5 \%$ of the subjects with fair/ poor $\mathrm{Ca}$ and vitamin D dietary intake had low vitamin D levels $(\mathrm{p}<0.05)$.

The DXA results revealed a statistically significant difference between the normal and the low vitamin D groups as regards to the T-score and Z-score of the left forearm $(\mathrm{p} \leq 0.05)$, spine $(\mathrm{p} \leq 0.05)$ and left femur $(\mathrm{p} \leq 0.05) \quad$ (Table 4). There were high statistically significant differences between the normal and low vitamin D groups as regards to the Beck score $(\mathrm{p} \leq 0.001)$ and the IPAQ score $(\mathrm{p} \leq$ 0.05), (Table 5).

There were statistically significant differences between individuals with insufficient vitamin D level and those with deficient levels as regards to the Beck score $(\mathrm{p} \leq 0.05)$ and BMD [T-score, $\mathrm{Z}$ score of (left forearm $(\mathrm{p} \leq 0.05$ and $\mathrm{p} \leq$ $0.05)$, femur $(\mathrm{p} \leq 0.05$ and $\mathrm{p} \leq 0.05)$ and spine $(\mathrm{p} \leq 0.05$ and $\mathrm{p} \leq 0.05)$ respectively). All parameters were worser in the deficient group; (Table 4 and 5).

On the other hand, there was a negative correlation between vitamin D levels and weight, BMI, ALP and Beck score. But there were insignificant correlations between vitamin D levels and age, height, PTH level, P level and BMD of the femur.

Table (6), shows correlations between vitamin $\mathrm{D}$ levels and total $\mathrm{Ca}$, ionized $\mathrm{Ca}$, $\mathrm{T}$ and Z-scores of the left forearm and spine and IPAQ score.

The female gender (OR 4.5; $\mathrm{p} \leq 0.05)$, older age group (>30-40 age group) (OR $4.4 ; \mathrm{p} \leq 0.05$ ), poor sun exposure (OR 7.8; $\mathrm{p} \leq 0.05$ ), and low vitamin $\mathrm{D}$ and calcium dietary intake (OR 4.6; $\mathrm{p} \leq 0.05)$, were the main risk factors for hypovitaminosis D.

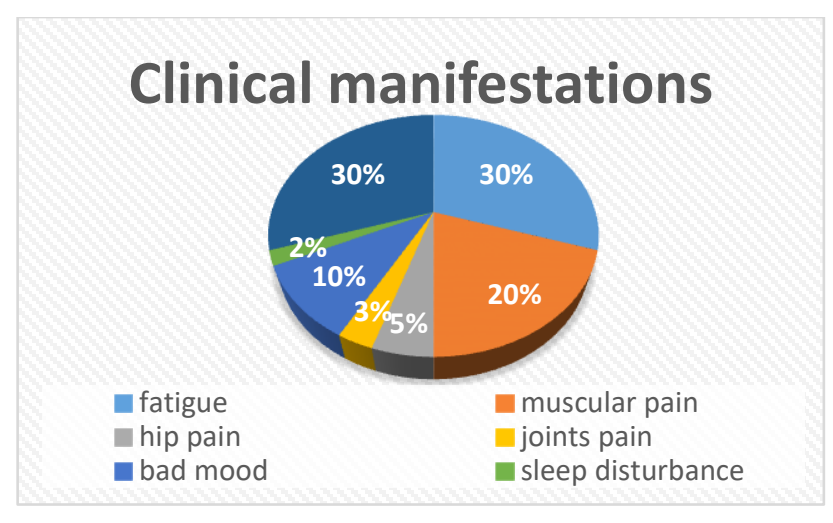

Figure 1: clinical manifestations in the studied groups 
Table (2): Comparisons between normal and low vitamin D status regarding the frequency of normal, overweight, and obese subjects

\begin{tabular}{lcccc}
\hline Vitamin D status & Normal BMI & Over weight & Obese & FET (p) \\
\hline Normal & 8 & 4 & 3 & \\
$(\mathbf{n = 1 5})$ & $53.3 \%$ & $26.7 \%$ & $20.0 \%$ & $*$ \\
Low & 4 & 14 & 22 & \\
$(\mathbf{n = 4 0 )}$ & $10 \%$ & $35 \%$ & $55 \%$ & \\
\hline
\end{tabular}

BMI: body mass index; $\mathrm{p} \leq 0.05 *$ is significant,

Table (3): Comparisons between the studied groups regarding anthropometric measurements

\begin{tabular}{|c|c|c|c|c|c|c|c|}
\hline \multirow[b]{2}{*}{ Weight (kg) } & \multirow{2}{*}{$\begin{array}{l}\text { Variable } \\
\text { Normal vitamin } D(n=15)\end{array}$} & \multirow{2}{*}{$\begin{array}{l}\text { Mean } \\
69.7 \\
\end{array}$} & \multirow{2}{*}{$\begin{array}{l} \pm \text { SD } \\
\\
14.3\end{array}$} & \multirow{2}{*}{\begin{tabular}{|l} 
Range \\
$55-98$
\end{tabular}} & \multirow{2}{*}{$\begin{array}{l}\text { P value } \\
<0.001 * *\end{array}$} & \multicolumn{2}{|c|}{$\begin{array}{l}\text { P values of multiple } \\
\text { comparisons (by } \\
\text { Bonferroni test) }\end{array}$} \\
\hline & & & & & & p1 & $0.006 *$ \\
\hline & Low vitamin $D(n=40)$ & 85.6 & 13.8 & $62-115$ & & p2 & $0.02 *$ \\
\hline & & & & & & p3 & 1.0 \\
\hline \multirow[t]{3}{*}{ Height (cm) } & Normal vitamin $D(n=15)$ & 163 & 7.13 & $150-173$ & 0.321 & p1 & 0.37 \\
\hline & Low vitamin $D(n=40)$ & 16407 & 4.95 & $152-180$ & & p2 & 1.0 \\
\hline & & & & & & p3 & 1.0 \\
\hline \multirow[t]{3}{*}{ BMI $\left(\mathrm{kg} / \mathrm{m}^{2}\right)$} & Normal vitamin $D(n=15)$ & 26.1 & 4.7 & $19.7-38.7$ & $0.001 * *$ & p1 & $0.031 *$ \\
\hline & Low vitamin $D(n=40)$ & 31.9 & 5.9 & $21.2-44.9$ & & p2 & $0.04 *$ \\
\hline & & & & & & p3 & 1.0 \\
\hline
\end{tabular}

SD: Standard deviation, BMI: Body mass index, $\mathrm{p}>0.05$ : non-significant, $\mathrm{p} \leq 0.05^{*}$ : significant, $\mathrm{p} \leq 0.001$ : highly significant; $\mathrm{p}$ : significance of difference between normal and low levels groups; $\mathrm{p} 1$ : significance of difference between normal and insufficiency groups; p2: significance of difference between normal and deficiency groups; 33 : significance of difference between insufficiency and deficiency group. 
Table (4): Comparisons between the studied groups regarding DXA results

\begin{tabular}{|c|c|c|c|c|c|c|c|}
\hline & & Variable & Median & Range & p values & $\begin{array}{r}\text { p valu } \\
\text { com } \\
\text { Bon }\end{array}$ & $\begin{array}{l}\text { multiple } \\
\text { ons (by } \\
\text { ni test) }\end{array}$ \\
\hline \multirow{9}{*}{ 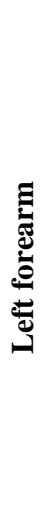 } & \multirow{3}{*}{$\sum_{\infty} \underbrace{\stackrel{\theta 0}{*}}_{\tilde{e}}$} & Normal vitamin $D(n=15)$ & 0.54 & $0.48-0.63$ & \multirow{3}{*}{0.139} & p1 & 1.0 \\
\hline & & \multirow{2}{*}{ Low vitamin $D(n=40)$} & \multirow{2}{*}{0.525} & \multirow{2}{*}{$0.48-0.64$} & & p2 & 0.41 \\
\hline & & & & & & p3 & 0.24 \\
\hline & \multirow{3}{*}{ 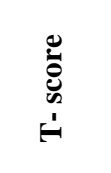 } & Normal vitamin $D(n=15)$ & 0.153 & $-0.8-1.1$ & \multirow{3}{*}{$<0.001 * *$} & p1 & 0.21 \\
\hline & & Low vitamin $D(n=40)$ & -072 & $-18-15$ & & p2 & $0.004 *$ \\
\hline & & & & & & p3 & 0.046 \\
\hline & \multirow{3}{*}{ 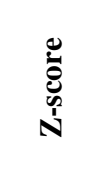 } & Normal vitamin $D(n=15)$ & -0.10 & $-1.0-1.1$ & \multirow{3}{*}{$0.003 *$} & p1 & 1.0 \\
\hline & & Jow vitamin D $(n-40)$ & -0755 & $10-14$ & & p2 & $0.014 *$ \\
\hline & & & & & & p3 & $0.029^{*}$ \\
\hline \multirow{9}{*}{$\stackrel{\mathscr{Z}}{\mathscr{2}}$} & \multirow{3}{*}{ 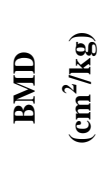 } & Normal vitamin D (n=15) & 1.03 & $0.96-1.22$ & \multirow{3}{*}{$0.029 *$} & p1 & 1.0 \\
\hline & & Low vitamin D $(n=40)$ & 008 & $088-121$ & & p2 & $0.049^{*}$ \\
\hline & & & & & & p3 & $0.021^{*}$ \\
\hline & \multirow{3}{*}{ 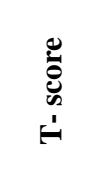 } & Normal vitamin $D(n=15)$ & 0.41 & $-0.6-1.6$ & \multirow{3}{*}{$<0.001 * *$} & p1 & 0.14 \\
\hline & & Jow vitamin D $(n-40)$ & -0495 & $16-15$ & & p2 & $0.002 *$ \\
\hline & & - & & 1.01 .0 & & p3 & $0.043^{*}$ \\
\hline & \multirow{3}{*}{ 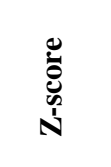 } & Normal vitamin D (n=15) & 0.41 & $-0.7-1.6$ & \multirow{3}{*}{$<0.001 * *$} & p1 & 0.16 \\
\hline & & Jow vitamin D $(n=40)$ & -0.05 & $-16-14$ & & p2 & $0.002 *$ \\
\hline & & & & & & p3 & $0.035^{*}$ \\
\hline \multirow{9}{*}{ 焉 } & \multirow{3}{*}{ 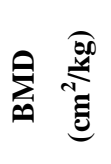 } & Normal vitamin D $(n=15)$ & 1.10 & $0.97-1.36$ & \multirow{3}{*}{0.075} & p1 & 1.0 \\
\hline & & Low vitamin $D(n=40)$ & 104 & $085-132$ & & p2 & 0.12 \\
\hline & & & & & & p3 & 0.099 \\
\hline & \multirow{3}{*}{ 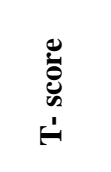 } & Normal vitamin $D(n=15)$ & 0.54 & $-0.6-2.0$ & \multirow{3}{*}{$0.028 *$} & p1 & 1.0 \\
\hline & & Low vitamin D $(n=40)$ & 0.235 & $-1.0-2.0$ & & p2 & 0.117 \\
\hline & & & & & & p3 & $0.024 *$ \\
\hline & \multirow{3}{*}{ 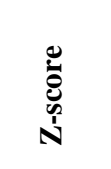 } & Normal vitamin $D(n=15)$ & 0.54 & $-0.6-2.0$ & \multirow{3}{*}{$0.018 *$} & p1 & 1.0 \\
\hline & & $\mathbf{I}$ & 005 & $10 \Omega \Omega$ & & p2 & 0.076 \\
\hline & & (20) & 0.200 & $-1.0-2.0$ & & p3 & $0.014 *$ \\
\hline
\end{tabular}

DXA: Dual x-ray absorptiometry; BMD: Bone mineral density; $p>0.05$ is non- significant; $p \leq 0.05$ : significant*; $p \leq 0.001^{* *}$ : highly significant. p: significance of difference between normal and low levels groups; p1: significance of difference between normal and insufficiency groups; p2: significance of difference between normal and deficiency groups; p3: significance of difference between insufficiency and deficiency group. 
Table (5): Comparisons between the studied groups regarding the scores of questionnaires

\begin{tabular}{|c|c|c|c|c|c|c|}
\hline \multicolumn{2}{|l|}{ Variable } & \multirow{2}{*}{$\begin{array}{l}\text { Median } \\
2019.0\end{array}$} & \multirow{2}{*}{$\begin{array}{l}\text { Range } \\
843-6919\end{array}$} & \multirow{2}{*}{ p values } & \multicolumn{2}{|c|}{$\begin{array}{l}\text { p values of multiple } \\
\text { comparisons (by Dune test) }\end{array}$} \\
\hline & normal vitamin $D(n=15)$ & & & & p1 & $0.029 *$ \\
\hline IPAQ score & low vitamin $D(n=40)$ & 591.0 & $269-7532$ & $0.015 *$ & $\begin{array}{l}\text { p2 } \\
\text { p3 }\end{array}$ & $\begin{array}{l}0.028^{*} \\
1.0\end{array}$ \\
\hline & normal vitamin $D(n=15)$ & 3.0 & $0.0-7.0$ & & p1 & $0.001 * *$ \\
\hline Beck score & low vitamin $D(n=40)$ & 13 & $0.0-25.0$ & $<0.001 * *$ & $\begin{array}{l}\text { p2 } \\
\text { p3 }\end{array}$ & $\begin{array}{l}0.001 * * \\
0.40\end{array}$ \\
\hline
\end{tabular}

Table (6) : Correlations between vitamin D levels and the studied variables

\begin{tabular}{|c|c|c|c|}
\hline \multirow{2}{*}{\multicolumn{2}{|c|}{ With }} & \multicolumn{2}{|c|}{ Serum 25 hydroxyvitamin D levels } \\
\hline & & Rho & $\mathbf{P}$ \\
\hline \multicolumn{2}{|c|}{ Age (ys) } & 0.212 & 0.12 \\
\hline \multicolumn{2}{|c|}{ Weight (kg) } & -0.400 & $0.002 *$ \\
\hline \multicolumn{2}{|c|}{ Height (cm) } & 0.067 & 0.63 \\
\hline \multicolumn{2}{|c|}{$\operatorname{BMI}\left(\mathrm{kg} / \mathrm{m}^{2}\right)$} & -0.459 & $<0.001 *$ \\
\hline \multicolumn{2}{|c|}{ Total Ca } & 0.655 & $<0.001 *$ \\
\hline \multicolumn{2}{|c|}{ Ionized Ca } & 0.495 & $<0.001 *$ \\
\hline \multicolumn{2}{|l|}{ PTH } & -0.108 & 0.43 \\
\hline \multicolumn{2}{|l|}{$\mathbf{P}$} & 0.061 & 0.66 \\
\hline \multicolumn{2}{|l|}{ ALP } & -0.275 & $0.042 *$ \\
\hline \multirow{4}{*}{ 氖 } & BMD & 0.260 & 0.072 \\
\hline & T-score & 0.444 & $=0.001 * *$ \\
\hline & Z-score & 0.476 & $=0.001 * *$ \\
\hline & BMD & 0.353 & $0.031 *$ \\
\hline \multirow{2}{*}{ 竞 } & T-score & 0.599 & $<0.001 * *$ \\
\hline & Z-score & 0.590 & $<0.001 * *$ \\
\hline \multirow{3}{*}{ 离 } & BMD & 0.085 & 0.56 \\
\hline & T-score & 0.022 & 0.88 \\
\hline & Z-score & 0.055 & 0.71 \\
\hline \multicolumn{2}{|c|}{ IPAQ score } & 0.430 & $=0.001 * *$ \\
\hline \multicolumn{2}{|c|}{ Beck score } & -0.653 & $<0.001 * *$ \\
\hline
\end{tabular}

rho: Spearman's correlation coefficient; $p$ : Probability value, $p>0.05$ : non-significant; $p \leq 0.05^{*}$ : significant; $p \leq 0.001 * *$ : highly significant. 


\section{Discussion}

Deficit vitamin D storage is an issue of medical interest in a wide age range [23]. Several conditions contribute to low serum levels of vitamin $\mathrm{D}$ in the general population, including poor dietary intake, sun avoidance and/or negligible sun exposure, impaired QoL, and malabsorption morbidities [24].

Hypovitaminosis D in adults results in bones and joint pains, muscle weakness, osteomalacia, and increased susceptibility to fractures. It is also associated with an increased risk of chronic disorders such as diabetes, cancers, depression, autoimmune, cardiovascular, and infectious diseases [15].

This study is proposed to determine some subclinical health consequences of hypovitaminosis D in healthy adult Egyptian population.

Our study was carried out on 55 apparently healthy volunteers, 36 females $(65.5 \%)$ and 19 males $(34.5 \%)$ whose ages ranged between 20 to 40 years. This study has identified a high prevalence of low vitamin D levels with mild clinical manifestation subtle to interfere with the daily activities but truly affect their QoL and accomplishment of function.

The main risk factors we came upon for low vitamin D levels in our subjects were female, poor sun exposure and low calcium and vitamin D dietary intake, obesity, low physical activity and depression were associated with low vitamin D.

An increased frequency of low vitamin D levels was documented in 40 subjects $(72.7 \%)$ of the study. Sixty-two percent (34\%) had insufficient levels and $10.9 \%$ (6\%) had deficient levels of vitamin D. These results confirmed the study of Sabila et al., [25], who reported vitamin D deficiency prevalence in 27 subjects (30\%) and insufficiency in 39 subjects $(34.3 \%)$ from their 90 studied healthy individuals. In contrast, a population-based study from Jordan found a surprisingly low frequency of vitamin D deficiency, as only $1.5 \%$ of males and about 14 $\%$ of females had vitamin D levels below 20 $\mathrm{ng} / \mathrm{ml}[26]$.

Regarding the age, our study showed that individuals between 31-40 years had low vitamin D levels more than those between 20-30 years. This result was close to the findings of AlQuaiz et al., [27] who described a high prevalence of vitamin D deficiency among the adult Saudi population aged from 30 to 75 years. In Boucher study, risk factors contributing to vitamin $\mathrm{D}$ deficiency in older adults included reduced nutritional intake of vitamin $D$, increasing adiposity, decreased cutaneous 
synthesis of vitamin D, disturbance in gut absorption of vitamin $\mathrm{D}$, and less time spent outdoors [28].

We found that the incidence of low vitamin D levels was more in females than males $(54.5 \%$ vs $18.1 \%$ respectively), which is parallel to Botros et al., [29] results who reported $34.3 \%$ of females vs $10.9 \%$ males of their studied Egyptians. In contrary, Lagunova et al.,[30] found that vitamin D deficiency was the same in all ages and both gender groups.

Regarding sun exposure, our results showed that subjects with fair and poor sun exposure were of low vitamin D levels (85\%). In the Middle East, people are inadequately exposed to sunlight due to their cloths' customs especially the veiled, beside the frequent topical application of sunscreen that decreases the vitamin D3 synthesis in the skin by $99 \%$ [31]. Studies have shown that at least $15 \%-20 \%$ of the body surface needs to be exposed to sunlight for a sufficient period of about 10-20 minutes for the synthesis of a sufficient amount of vitamin D [32].

We also reported that studied subjects with fair and poor dietary $\mathrm{Ca}$ and vitamin $\mathrm{D}$ were associated with 4.6-folds increased odds of decreased vitamin D in their serum. This was consistent with Alhaddad et al., [33] study on sample of premenopausal women (aged 20-50 years) in Jeddah that found subjects did not consume sufficient amounts of dietary vitamin D and calcium to meet the daily requirements for this age group.

In our subjects, we noticed that there was a highly significant negative correlation $(r=$ $0.459, \mathrm{p} \leq \mathbf{0 . 0 0 1})$ between $\mathrm{BMI}$ and vitamin $\mathrm{D}$ level with obesity prevalent in $45.5 \%$ of subjects. Similar results were reported by several studies [34, 35]. Obesity is associated with an increased risk of low vitamin D status due in part to decreased bioavailability of circulating 25-hydroxyvitamin D (25OHD) that is sequestered by the body fat before being transported to the liver for the first hydroxylation. At the same time, low vitamin D status may promote adipogenesis, potentially resulting in further increases in adiposity [36].

Moreover, it is worth to be noted that there were worse results of Beck score and BMI, $\mathrm{T}$ - score and Z- score of DEXA in the subjects with deficient vitamin $\mathrm{D}$ levels than those with insufficient levels. There was a statistically significant difference between insufficiency and deficiency groups $(\mathrm{p} \leq 0.05)$ as regards $\mathrm{T}$-score and Z-score of left forearm, left femur, and spine (being higher in the vitamin D deficient group) and BMD of spine. That emphasizes the effect of vitamin D of these parameters on individuals' health.

Persons who had low vitamin D levels had T and Z-score of left forearm [(r=0.444,p=0.001 ) $(r=$ $0.476, \mathrm{p}=0.001)]$ and $\operatorname{spine}[(\mathrm{r}=0.599, \mathrm{p}<0.001$ )$(\mathrm{r}=0.590, \mathrm{p}<0.001)]$ and BMD of $\operatorname{spine}(\mathrm{r}=$ 
$0.353, \mathrm{p}=0.031$ ) of DEXA correlating positively with vitamin D levels. This coincided with the results of Ghannam et al., [41].

Conversely, Garnero et al., [42] and Allali et al., [43] failed to show any significant correlation between 25 OHD levels and BMD after adjusting for age. The above controversial findings can be partially explained by the differences in populations, age groups, country's wearing customs, dietary variations and differences in the body sites studied by DEXA.

We found a positive correlation of serum vitamin D level with serum levels of total $\mathrm{Ca}$ $(\boldsymbol{r}=0.655, \boldsymbol{p} \leq \mathbf{0 . 0 0 1})$ and ionized $\mathrm{Ca},(\boldsymbol{r}=0.495$, $\boldsymbol{p} \leq \mathbf{0 . 0 0 1}$ ) and a negative correlation with ALP level $(\boldsymbol{r}=-0.275, \mathrm{p}=0.042 \quad)$. This agreed with the results of Al Alwan et al., [37].

On the other hand, we found that there was insignificant correlations of serum vitamin $D$ levels with PTH $(r=-0.108, \mathrm{p}=0.43)$ or P levels $(\boldsymbol{r}=0.061, \mathrm{p}=0.042)$ which matched Amouzougan et al., [38] and Sahota et al., [39] results who reported normal PTH levels associating low vitamin D levels. This may be explained by the presence of functional hypoparathyroidism which is a state in which serum PTH levels do not increase despite vitamin D deficiency even with low serum $25(\mathrm{OH}) \mathrm{D}$ levels. This condition is inducted by the slight reduction of serum calcium due to the failure of the parathyroid gland to mount an adequate parathyroid hormone [40].
A high median score of Beck questionnaire that measures depression risk and level of severity was observed in the low vitamin D group compared to normal vitamin D group (19.5 (6.619.9) $\mathrm{ng} / \mathrm{L}$ vs 32 (30.1-36.5) ng/L). Also, we found a significant negative correlation of this questionnaire with the serum vitamin $\mathrm{D}(\boldsymbol{r}=$ $0.653, \boldsymbol{p} \leq \mathbf{0 . 0 0 1})$. These data agreed with the cross-sectional study of Scherchand et al. [44] among the adult population in Nepal who found that $16.3 \%$ of their subjects had clinically significant depression which was higher among vitamin $\mathrm{D}$ deficient individuals in comparison to individuals with sufficient vitamin $D$. The association between the onset of depression due to vitamin D deficiency is based on the effect of vitamin $\mathrm{D}$ to preclude depression by maintaining normal serotonin levels in the brain through regulating the expression of serotonergic gene coding for tryptophan hydroxylase, a key limiting enzyme of serotonin synthesis [45].

Our results showed a significant positive correlation between serum vitamin $\mathrm{D}$ status and physical activity $(\boldsymbol{r}=0.430, \mathrm{p}=0.001)$ with a low median score of the IPAQ questionnaire in low vitamin $\mathrm{D}$ group as compared to normal vitamin D group. These findings were consistent with Ward et al., [46] who conveyed that in vitamin D insufficient, young adolescent girls showed a correlation between vitamin D levels and muscle power, force, velocity, and jump height. It is known that vitamin $\mathrm{D}$ acts directly on skeletal muscle function that maintains the skeletal 
muscle mass, strength and speed of contraction. Low vitamin D levels correlated with impaired skeletal muscle function, accumulation of muscle fat, increased circulation of proinflammatory cytokines and decreased circulation of anti-inflammatory cytokines. In addition to osteomalacia, low vitamin D levels has been associated with muscle weakness and hypotonia [47].

On the contrary, Matheï et al., [48] reported $80 \%$ prevalence of vitamin D insufficiency with no evident correlation found between vitamin D levels and physical performance, as assessed by gait speed, handgrip test, and a static balance test.

The limitation of our study was the limited number of subjects as they were recruited from one area. We concluded that hypovitaminosis D is a frequent subtle condition in the healthy Egyptians that has a great impact on their physical, functional, mental and emotional health. We recommend for vitamin D level check-up even in young individuals and constant supplementation in foods or drugs.

\section{References:}

1. Walsh JS, Bowles S, Evans AL .Vitamin D in obesity. Curr. Opin. Endocrinal. Diabetes Obes. 2017; 24,389-394.

2. Calvo MS, Whiting SJ, Barton CN. Vitamin D intake: a global perspective of current status. J Nutr. 2005; 135(2):310-16
3. Amr N, Hamid A, Sheta M, \& Elsedfy H.Vitamin D status in healthy Egyptian adolescent girls. Georgian medical news.2012; (210), 65-71.

4. Arabi A, El Rassi R, \& Fuleihan GE. Hypovitaminosis D in developing countries-prevalence, risk factors and outcomes. Nature Reviews Endocrinology.2010; 6(10), 550.

5. Carmina E.: Vitamin D: Biological Significance and Diagnosis of Mild Deficiency. Biomarkers in Bone Disease.2019; 393-405.

6. Suda T, Masuyama R, Bouillon $R, \&$ Carmeliet G. Physiological functions of vitamin D: what we have learned from global and conditional VDR knockout mouse studies. Current Opinion in Pharmacology.2015; 22, 87-99.

7. Chun RF, Liu PT, Modlin RL, Adams JS, \& Hewison M. Impact of vitamin D on immune function: lessons learned from genome-wide analysis. Frontiers in physiology.2014; 5, 151.

8. Almeida LF, \& Coimbra TM. Vitamin D actions on cell differentiation, proliferation and inflammation. Int $\mathbf{J}$ Complement Alt Med.2017; 6(5), 00201.

9. Sabir MS, Haussler M R, Mallick S, Kaneko I, Lucas DA, Haussler CA ., et al. Optimal vitamin D spurs serotonin: 1, 25dihydroxyvitamin $\mathrm{D}$ represses serotonin reuptake transport (SERT) and degradation (MAO-A) gene expression in cultured rat serotonergic neuronal cell lines. Genes \& nutrition.2018; 13(1), 19. 
10. Gezen-Ak D, Dursun E, \& Yilmazer S.

The effect of vitamin D treatment on nerve growth factor (NGF) release from hippocampal neurons. Nöro Psikiyatri Arşivi.2014; 51(2), 157.

11. Brewer LD, Thibault V, Chen KC, Langub MC, Landfield PW, \& Porter NM. Vitamin D hormone confers neuroprotection in parallel with downregulation of L-type calcium channel expression in hippocampal neurons. Journal of Neuroscience.2001; 21(1), 98-108.

12. Wrzosek M, Lukaszkiewicz J, Wrzosek M, Jakubczyk A, Matsumoto H, Piątkiewicz P., et al. Vitamin D and the central nervous system. Pharmacological reports.2013; 65(2), 271-278.

13. Eyles DW, Burne TH, \& McGrath JJ. Vitamin D, effects on brain development, adult brain function and the links between low levels of vitamin D and neuropsychiatric disease. Frontiers in neuroendocrinology.2013; 34(1), 47-64.

14. Moy FM, Hoe VC, Hairi NN, Vethakkan SR, \& Bulgiba A. Vitamin D deficiency and depression among women from an urban community in a tropical country. Public health nutrition.2017; 20(10), 18441850.

15. Canbay E. Vitamin D Deficiency: Causes \& Treatment, Vol. 1, pp. 1-103. Vitamin D Deficiency: Causes \& Treatment. 2019; 2:4.

16. Holick MF, Binkley NC, Bischoff-Ferrari HA, Gordon CM, Hanley DA, Heaney $\mathbf{R P}$, et al. Evaluation, treatment, and prevention of vitamin D deficiency: an
Endocrine Society clinical practice guideline. The Journal of Clinical Endocrinology \& Metabolism.2011; 96(7), 1911-1930.

17. Holick MF. Vitamin D: a d-lightful solution for health. Journal of Investigative Medicine.2011; 59(6), 872-880.

18. Beck AT, Steer RA, Brown GK. Manual for the beck depression inventory-II. San Antonio, TX: Psychological Corporation. 1996; 1:82.

19. Ghareeb AG. Manual of the Arabic BDI-II. Alongo Press. Cairo Inventory: the author's twenty-five years of evaluation. Clin Psychol Rev.2000; 8, 77-100.

20. Booth M. Assessment of physical activity: an international perspective. Research quarterly for exercise and sport.2000; 71(sup2), 114-120.

21. Bartl R, Frisch B. Osteoporosis: diagnosis, prevention, therapy. Springer Science \& Business Media; 2009 May 12.

22. Kanis JA. Assessment of osteoporosis at the primary health-care level. WHO Collaborating Centre for Metabolic Bone Diseases, University of Sheffield. 2007 May 17.

23. Holick MF. The vitamin D deficiency pandemic: approaches for diagnosis, treatment and prevention. Reviews in Endocrine and Metabolic Disorders.2017;18(2), 153-165.

24. Jungert A, \& Neuhäuser-Berthold $M$. Sex-specific determinants of serum 25hydroxyvitamin D 3 concentrations in an elderly German cohort: a cross-sectional 
study. Nutrition \& metabolism.2015; 12(1), 2.

25. Sabila M, Sahar I, Nagwa M, Omima A .Measurement of Serum Vitamin D25 Level in Normal Egyptian Population, Clinical Medicine and Diagnostics.2018; Vol. 8 No. 4, pp. 63-68. doi: 10.5923/j.cmd.20180804.02.

26. Batieha A, Khader Y, Jaddou H, Hyassat D, Batieha Z, Khateeb M., et al. Vitamin D status in Jordan: dress styleand gender discrepancies. Ann Nutr Metab .2011; 58:10-18

27. AlQuaiz AM, Kazi A, Fouda M \& Alyousefi N. Age and gender differences in the prevalence and correlates of vitamin $\mathrm{D}$ deficiency. Archives of osteoporosis.2018; 13(1), 49.

28. Boucher BJ. The problems of vitamin $d$ insufficiency in older people. Aging and disease.2012; 3(4), 313.

29. Botros R, Al SH, Mansour H, Guirgis M. High prevalence of severe vitamin D deficiency in Egyptian females. In21st European Congress of Endocrinology 2019 May 1 (Vol. 6). BioScientifica.

30. Lagunova Z, Porojnicu AC, Lindberg F, Hexeberg S \& Moan J. The dependency of vitamin $\mathrm{D}$ status on body mass index, gender, age and season. Anticancer research.2009;29(9), 3713-3720.

31. Wang SQ, Balagula Y \& Osterwalder U. Photoprotection: a review of the current and future technologies. Dermatologic therapy.2010; 23(1), 31-47.
32. Holick MF. Photobiology of vitamin D. Invitamin D 2018 Jan 1 (pp. 45-55). Academic Press.

33. Al-Haddad FA, Al-Mahroos FT, AlSahlawi HS \& Al-Amer E. The impact of dietary intake and sun exposure on vitamin D deficiency among couples. Bahrain Medical Bulletin.2014; 158(1188), 1-5

34. Ramel A, Jonsson PV, Bjornsson S, \& Thorsdottir I. Vitamin D deficiency and nutritional status in elderly hospitalized subjects in Iceland. Public health nutrition.2009; 12(7), 1001-1005.

35. Man RE, Li LJ, Cheng CY, Wong TY, Lamoureux $E$ and Sabanayagam $C$ .Prevalence and Determinants of Suboptimal Vitamin D Levels in a Multiethnic Asian Population. Nutrients.2017;22: 9(3).

36. Scott D, Ebeling PR, Sanders KM, Aitken D, Winzenberg T, \& Jones G. Vitamin D and physical activity status: associations with five-year changes in body composition and muscle function in community-dwelling older adults. The Journal of Clinical Endocrinology \& Metabolism.2015; 100(2), 670-678.

37. Al Alwan I, Al Badi M, Badri M, Tamimi W, Al Dubayee M, Mughal MZ, et al. Higher serum alkaline phosphatase activity in infants born to vitamin D-deficient mothers. Archives of osteoporosis.2019; 14(1), 102.

38. Amouzougan A, Chopin F, Laporte S, Vico L, \& Thomas T. Functional hypoparathyroidism in postmenopausal women with fragility fracture. Joint Bone Spine.2012; 79(2), 170-175. 
39. Sahota O, Mundey MK, San P, Godber IM, Lawson N, \& Hosking DJ. The relationship between vitamin $\mathrm{D}$ and parathyroid hormone: calcium homeostasis, bone turnover, and bone mineral density in postmenopausal women with established osteoporosis. Bone.2004; 35(1), 312-319.

40. Sahota O, Gaynor K, Harwood RH, \& Hosking DJ. Hypovitaminosis D and 'functional hypoparathyroidism'-the NoNoF (Nottingham Neck of Femur Study). Age and ageing.2003; 32(4), 465-466.

41. Ghannam NN., Hammami MM., Bakheet SM., \& Khan BA. Bone mineral density of the spine and femur in healthy Saudi females: relation to vitamin $\mathrm{D}$ status, pregnancy, and lactation. Calcified tissue international.1999; 65(1), 23-28.

42. Garnero P, Munoz F, Sornay-Rendu E, \& Delmas PD. Associations of vitamin D status with bone mineral density, bone turnover, bone loss and fracture risk in healthy postmenopausal women. The OFELY study. Bone.2007; 40(3), 716-722.

43. Allali F., El Aichaoui S., Khazani H., Benyahia B., Saoud B., El Kabbaj S., et al. High prevalence of hypovitaminosis D in Morocco: relationship to lifestyle, physical performance, bone markers, and bone mineral density. In Seminars in arthritis and rheumatism.2009; (Vol. 38, No. 6, pp. 444451). WB Saunders.
44. Sherchand O., Sapkota N., Chaudhari RK., Khan SA., Baranwal JK., Pokhrel, T., et al. Association between vitamin D deficiency and depression in Nepalese population. Psychiatry research.2018; 267, 266-271.

45. Kaneko I., Sabir M. S., Dussik CM., Whitfield GK., Karrys A., Hsieh JC., et al. 1, 25-Dihydroxyvitamin D regulates expression of the tryptophan hydroxylase 2 and leptin genes: implication for behavioral influences of vitamin D. The FASEB Journal.2015; 29(9), 4023-4035.

46. Ward KA., Das G., Berry JL., Roberts SA., Rawer R., Adams JE., et al. Vitamin D status and muscle function in postmenarchal adolescent girls. The Journal of Clinical Endocrinology \& Metabolism.2009; 94(2), 559-563.

47. Fitzgerald JS., Peterson BJ., Wilson PB., Rhodes GS., \& Ingraham SJ. Vitamin D status is associated with adiposity in male ice hockey players. Medicine and Science in Sports \& Exercise.2015; 47(3), 655-661.

48. Matheï C., Van Pottelbergh G., Vaes B., Adriaensen W., Gruson D., \& Degryse M. No relation between vitamin D status and physical performance in the oldest old: results from the Belfrail study. Age and ageing.2013;42(2), 186-190.

To cite this article: Sahar S. Ganeb, Refaat M. Eltanawy' Yasmin M. Marei , Hadir M.Abdelazez, Marwa Y. Mahgoub. Implications of vitamin D Deficiency on Egyptian Adult's Health, BMFJ 2021;38(3):831-847. DOI: 10.21608/bmfj.2021.39559.1308 